Pesq. Vet. Bras. 30(8):613-617, agosto 2010

\title{
Surto de polioencefalomalacia por ingestão excessiva de enxofre na dieta em bezerros no Rio Grande do Sul ${ }^{1}$
}

\author{
Paulo H.J. da Cunha², Paulo M. Bandarra ${ }^{3}$, Marcelo M. Dias ${ }^{4}$, Alexandre S. \\ Borges $^{5}$ e David Driemeier ${ }^{3}$
}

\begin{abstract}
Cunha P.H.J., Bandarra P.M., Dias M.M., Borges A.S. \& Driemeier D. 2010. [Outbreak of polioencephalomalacia in cattle consuming high sulphur diet in Rio Grande do Sul, Brazil.] Surto de polioencefalomalacia por ingestão excessiva de enxofre na dieta em bezerros no Rio Grande do Sul. Pesquisa Veterinária Brasileira 30(8):613-617. Departamento de Medicina Veterinária, Escola de Veterinária, Universidade Federal de Goiás, Campus Samambaia, Cx. Postal 131, Goiânia, GO 74001-970, Brazil. E-mail: phcunhavet@yahoo.com.br

An outbreak of polioencephalomalacia in cattle caused by ingestion of high sulphur diet, in Rio Grande do Sul, Brazil is described. One group of 30 calves was kept in Italian ryegrass (Lolium multiflorum) pasture and supplemented with concentrate and minerals. Six calves died, necropsy was performed in two of them and liver samples (for lead determination) and fragments of central nervous system were collected. Clinical and neurological examination was performed in one calf and confirmed brain involvement. Sulphur content on dietary components and water, ruminal hydrogen sulfide production in five calves of the same group and PCR from formalin-fixed paraffin-embedded cerebral tissues to detect bovine herpesvirus 5 DNA was perfomed. The total sulphur intake was $0.38 \%$ dry matter and the values of ruminal sulfide concentration ranged from 1,000 to 2,500ppm. Lead It was not detected in the liver samples and PCR was negative for bovine herpesvirus 5 . The brain lesions were characterized by laminar neuronal necrosis. The clinical signs of cerebrocortical syndrome associated with high ruminal sulfide values, elevated intake of dietary sulphur and histological lesions confirmed that the excess of sulphur caused the polioencephalomacia in these calves.
\end{abstract}

INDEX TERMS: Cerebrocortical necrosis, diagnostic, ruminal hydrogen sulfide.

RESUMO.- Neste trabalho descreve-se surto de polioencefalomalacia em bovinos decorrente da ingestão de dieta com excessiva concentração de enxofre em uma propriedade no Rio Grande do Sul. O lote era composto por 30 bezerros, mantidos em um piquete com azevém (Lolium multiflorum) e suplementados com ração e sal mineral. Seis bezerros mor-

\footnotetext{
${ }^{1}$ Recebido em 12 de janeiro de 2010.

Aceito para publicação em 25 de janeiro de 2010.

2 Departamento de Medicina Veterinária, Escola de Veterinária, Universidade Federal de Goiás (UFG), Campus Samambaia (Campus II), Cx. Postal 131, Goiânia, GO 74001-970, Brasil. *Autor para correspondência:phcunhavet@yahoo.com.br

${ }^{3}$ Setor de Patologia Veterinária, Faculdade de Veterinária, Universidade Federal do Rio Grande do Sul (UFRGS), Av. Bento Gonçalves 9090, Porto Alegre, RS 91540-000, Brasil.

${ }^{4}$ Médico Veterinário Autônomo, Rua liberdade, 432, apto 201, Bairro Rio Branco. Porto Alegre, RS 90420-090.

${ }^{5}$ Departamento de Clínica Veterinária, Faculdade de Medicina Veterinária e Zootecnia, Universidade Estadual Paulista (Unesp), Campus de Botucatu, Distrito de Rubião Júnior s/n, Botucatu, SP 18618-000, Brasil.
}

reram e dois deles foram necropsiados; amostras de tecido hepático para dosagem de chumbo e fragmentos do sistema nervoso central para histopatológico foram colhidos. Um dos bezerros foi examinado antes da morte e sinais neurológicos encefálicos foram constatados. Foi estabelecido o teor de enxofre nos componentes da dieta e água, a produção de sulfeto de hidrogênio ruminal em cinco bovinos do mesmo lote e realizada PCR de um bloco de parafina para detecção de DNA do herpevirus bovino tipo 5. O consumo total de enxofre foi de $0,38 \%$ da matéria seca fornecida aos animais e as dosagens de sulfeto de hidrogênio ruminal em animais do mesmo lote variaram de 1.000 a $2.500 \mathrm{ppm}$. Os achados histopatológicos indicaram necrose laminar do córtex cerebral. Não foi detectado chumbo na amostra de tecido hepático e não foi identificado DNA do herpesvirus bovino tipo 5 no encéfalo. O quadro clínico de síndrome cerebrocortical associado aos elevados valores do sulfeto de hidrogênio ruminal, alta ingestão de enxofre na dieta e os achados histopatológicos permitem estabelecer o excesso de enxofre como causador da polioencefalomalacia. 
TERMOS DE INDEXAÇÃO: Necrose cerebrocortical, diagnóstico, sulfeto de hidrogênio.

\section{INTRODUÇÃO}

A polioencefalomalacia (PEM) é uma alteração morfológica caracterizada por amolecimento (malacia) da substância cinzenta (polio) do encéfalo. A primeira descrição da PEM foi relatada por Jensen et al. (1956) e durante os 25 anos subsequentes, a etiologia foi atribuída à deficiência de tiamina (Gould 2000). Porém, pesquisas têm indicado que os achados clínicos e histopatológicos são similares entre as diversas causas de PEM (Gould 2000, Burgess 2008, Sant'Ana et al. 2009a,b).

A associação entre dietas com alto teor de enxofre e a ocorrência de PEM em bovinos foi confirmada por vários autores, tanto na forma de surtos (Coghlin 1944, Dickie etal. 1979, Raisbeck 1982, Hibbs \& Thilsted 1983, Haris 1987, Beke \& Hironata 1991, Hamlen et al. 1993, Jeffrey et al. 1994, Bulgin et al. 1996, Low et al. 1996, McAllister et al. 1997, Niles et al. 2000, Traverso et al. 2001, Haydock2003, Kul etal. 2006, McKenzie etal. 2009) ou por induções experimentais (Mella etal. 1976, Sager etal.1990, Gould etal. 1991, McAllister etal. 1992, Cummings etal. 1995 Gould etal. 1997, Niles et al. 2002, Loneragan et al 2005, Cunha et al., 2008).

No Brasil, com exceção de um relato de PEM no Rio Grande do Sul (Traverso et al. 2001), as demais descrições em diversos Estados brasileiros (MS, SP, RS, MG, GO, MT, PE, PB, PA), não estabeleceram a participação do enxofre na etiologia desta encefalopatia em bovinos a pasto (Lima et al. 2005).

A forma mais adequada de diagnosticar PEM causada por enxofre é a determinação do teor de enxofre na dieta e na água associada à dosagem da concentração do sulfeto de hidrogênio ruminal (Gould 2000). Todas essas informações associadas aos achados de necropsia e histopatologia permitem estabelecer a participação do enxofre nos casos de PEM, bem como auxiliar no diagnóstico diferencial de outras causas de encefalopatias (Barros et al. 2006).

Este artigo relata um surto de polioencefalomalacia em bezerros no Rio Grande do Sul, descrevendo as alterações clínicas, os resultados da dosagem do sulfeto de hidrogênio ruminal, o consumo total de enxofre na dieta e na água e os achados histopatológicos.

\section{MATERIAL E MÉTODOS}

Dados epidemiológicos e sinais clínicos da enfermidade foram obtidos com o proprietário e o médico veterinário que atendia o rebanho em uma propriedade localizada a 100 km de Porto Alegre, Rio Grande do Sul.

O lote de bovinos afetados era constituído por 30 bovinos da raça Red Angus, com idade variando de 10 a 12 meses, pesando aproximadamente $200 \mathrm{~kg}$ e criados em sistema de semi-confinamento, mantidos em um piquete com azevém (Lolium multiflorum.) e suplementados com $1 \%$ PV de ração comercial $^{6}$ e sal mineral ${ }^{7}$.

As amostras do azevém foram colhidas em diferentes pontos do piquete e as determinações da concentração do enxofre nesta forragem $(2.300 \mathrm{mg} / \mathrm{kg})$, na ração $(2.550 \mathrm{mg} / \mathrm{kg})$ e no suplemento mineral $(13.500 \mathrm{mg} / \mathrm{kg})$ foram realizadas no Instituto Campineiro de Análise de Solo e Adubo Ltda. As dosagens de enxofre na água do bebedouro $(2,4 \mathrm{mg} / \mathrm{L})$ foi realizada no Laboratório de Nutrição Mineral de Plantas e de Fertilizantes e Corretivos da Faculdade de Ciências Agronômicas da Unesp-Botucatu.

A técnica da dosagem de sulfeto de hidrogênio (gás sulfídrico ou $\mathrm{H}_{2} \mathrm{~S}$ ) ruminal utilizada foi adaptada de Gould et al. (1997) com as modificações descritas a seguir. Inicialmente foi realizada a tricotomia da fossa paralombar esquerda e anti-sepsia com iodopovidona (PVPI), sendo que a punção ruminal foi realizada no ponto médio da porção mais dorsal da fossa paralombar esquerda utilizando-se agulha do cateter intravenoso $14 \mathrm{G}$ sem a cânula externa de teflon. Em seguida, foi encaixado ao conector da agulha um equipo intravenoso com $15 \mathrm{~cm}$ de comprimento, cortando e desprezando-se a extremidade com o gotejador. A ponta cortada do equipo adaptado foi acoplada ao tubo colorimétrico ${ }^{8}$ de dosagem de gás sulfídrico, que já estava previamente inserido na bomba manual de vácuo ${ }^{9}$. As mensurações foram realizadas de acordo com o manual do fabricante da bomba de vácuo, padronizando em $100 \mathrm{~mL}$ de gás para valores entre 1.000 e $40.000 p p m$ de sulfeto de hidrogênio com tempo de amostragem de 1,5 minutos.

Em um bovino foi realizado exame físico geral e específico do sistema nervoso central de acordo com Dirksen et al. (1993).

Dois bovinos foram necropsiados, um após a morte natural e outro eutanasiado in extremis. Amostras de tecido hepático foram coletadas para dosagem de chumbo, enquanto fragmentos encefálicos (porção caudal do telencéfalo, o tálamo, o vermix do cerebelo e a porção final do tronco encefálico) foram congelados e encaminhados para exame de imunofluorescência direta para diagnóstico diferencial de raiva. As porções restantes do telencéfalo, do cerebelo, o tronco encefálico e o monobloco contendo os gânglios do trigêmio e a "rede mirabile" foram fixados em formol a $10 \%$ para realização do exame histopatológico para diagnóstico diferencial das encefalopatias. Posteriormente, foi separado um bloco de parafina de uma região do encéfalo que apresentava lesão sugestiva de PEM para realizar a técnica da PCR para detecção do DNA do herpesvírus bovino tipo 5. A extração do DNA dos blocos de parafina foi realizada com DNA FFPE Tissue kit $^{10}$ e a técnica da PCR foi realizada segundo protocolo estabelecido por Claus et al. (2005).

\section{RESULTADOS E DISCUSSÃO}

Seis bovinos morreram, em um intervalo de 10 dias, apresentando manifestação clínica caracterizada por apatia, anorexia, incoordenação motora, cegueira, opistótono, movimentos de pedalagem, coma e morte 48-72 horas após o surgimento dos primeiros sinais clínicos. Esses sinais observados indicaram quadro de síndrome cerebrocortical nos

\footnotetext{
${ }^{6}$ Supra Maxxinovilho ${ }^{\circledR}$ Supra, Rua João Carlos Von Honendorff 900, São Leopoldo, RS.

7 GadoForte 80. GadoForte, Rua Voluntários da Pátria 2432, Porto Alegre, RS.

8 Tubos colorimétricos modelo $120 \mathrm{SH}$, Sensidyne ${ }^{\circledR}$, Sensidyne Industrial Health and Safety Instrumentation, Florida, USA. Representante no Brasil: Almont do Brasil, Rua Horácio de Castilho 284, Vila Maria Alta, São Paulo, SP.

${ }^{9}$ Bomba modelo AP-20S, Sensidyne ${ }^{\circledR}$, Sensidyne Industrial Health and Safety Instrumentation, Florida, USA. Representante no Brasil: Almont do Brasil, Rua Horácio de Castilho 284, Vila Maria Alta, São Paulo, SP.

${ }^{10}$ QIAamp ${ }^{\circledR}$. Qiagen Biotecnologia Brasil Ltda, Av. Jabaquara 1909, São Paulo, SP
} 
bovinos (Borges et al. 1999) e foram semelhantes aos relatados por Rousseaux et al (1991), McAllister et al. (1992), Jeffrey et al (1994), Gould (2000), Burgess (2008), Sant'Ana et al. (2009a,b). No estudo retrospectivo realizado por Sant'Ana et al. (2009a), o curso clínico da maioria dos casos de PEM variou de dois a quatro dias, semelhante ao observado nestes animais.

Dois bovinos foram necropsiados e apresentaram macroscopicamente hemorragias no tecido subcutâneo e cérebro levemente amarelado com diminuição das circunvoluções. A tumefação com achatamento das circunvoluções cerebrais foi também descrita por Jensen et al. (1956), Jeffrey et al. (1994), Nakazato et al. 2000, Lemos (2005) e Sant'Ana et al. (2009a,b) nos casos de PEM.

O exame macroscópico sob aplicação da luz ultravioleta no comprimento de $365 \mathrm{~nm}$ foi realizado e em determinados segmentos transversais do córtex cerebral observou-se a autofluorescência, indicando que as lesões eram sugestivas de PEM (Gould 2000).

Na microscopia havia necrose laminar do córtex cerebral associado a edema perivascular e perineuronal e neurônios vacuolizados, enrugados, de aspecto angular e com citoplasma eosinofílico. As alterações histológicas observadas no encéfalo dos bovinos afetados por PEM neste surto foram muito semelhantes aos descritos por outros autores em casos de PEM causado por ingestão excessiva de enxofre (Jensen et al. 1956, Jeffrey et al. 1994, Nakazato et al. 2000, Lemos 2005, Barros et al. 2006, Sant'Ana et al. (2009a,b).

Em relação ao consumo de enxofre pelos bovinos, considerou-se que um animal pesando $200 \mathrm{~kg}$ teve uma ingestão de matéria seca equivalente a $2,5 \%$ do peso vivo, divididos em 2 $\mathrm{kg}$ de ração (1\% peso vivo) e $3 \mathrm{~kg}$ do azevém, sendo estimado um consumo de $2.400 \mathrm{mg}$ de enxofre por $\mathrm{kg}$ de matéria seca. A ingestão do suplemento mineral foi estabelecida em $0,1 \mathrm{~kg}$ por dia, acarretando um consumo de enxofre de $1.350 \mathrm{mg} / \mathrm{kg}$. Para estabelecer o consumo de enxofre na água foi estabelecido, de acordo com Winchester \& Morris (1956), que um bovino de $200 \mathrm{~kg}$ mantido em temperatura ambiente de $28^{\circ} \mathrm{C}$ deve ingerir 26 litros de água por dia, totalizando uma ingestão de $62,4 \mathrm{mg}$ de enxofre por dia por animal. A soma da concentração de enxofre nas diversas fontes (ração, volumoso, suplemento mineral e água) totalizou um consumo de aproximadamente $3.800 \mathrm{mg} / \mathrm{kg}$ na matéria seca, indicando ingestão excessiva de enxofre, visto que, Klasing et al. (2005) recomendam consumo de $1.500 \mathrm{mg} / \mathrm{kg}$ para gado de corte; de acordo com esses autores, concentrações de enxofre acima de $3.000 \mathrm{mg} / \mathrm{kg}$ na matéria seca, como estimada neste surto, podem ocasionar PEM. Sager et al (1990) e Gould et al. (1997) induziram polioencefalomalacia em bovinos fornecendo dieta que continha aproximadamente $3.600 \mathrm{mg}$ de enxofre por $\mathrm{kg}$ na matéria seca, sendo este valor inferior a concentração total estimada neste surto no Rio Grande do Sul.

Na região sul, o azevém (Lolium multiflorum) é a espécie forrageira de estação fria amplamente utilizada na formação de pastagens para suprir a carência alimentar dos rebanhos. Sua grande utilização dá-se devido a algumas característi- cas, como a facilidade de ressemeadura natural, estabelecimento em sucessão a produção de grãos, principalmente em áreas de soja, pela adaptação a solos com diferentes aptidões de uso agrícola. Acrescenta a estas vantagens a boa palatabilidade, alto valor nutritivo, elevada produção de forragem e facilidade de ser utilizado em consorciação com outras espécies forrageira (Roso 2007). No presente surto este tipo de pastagem apresentou um teor de enxofre de $2.300 \mathrm{mg} /$ kg na matéria seca, sendo esta concentração bem acima do valor de referência para o azevem $(1.000 \mathrm{mg} / \mathrm{kg})$ estabelecido pelo NRC (2000). Além disso, pesquisas realizadas nos Estados do Rio de Janeiro (Tebaldi et al. 2000), São Paulo (Barreto Junior 2008) e Rio Grande do Sul (Wunsch et al. 2006) avaliando a concentração de enxofre em capins, corroboraram os resultados obtidos com valores próximos ao indicado pelo NRC (2000) sugerindo que este alto teor de enxofre identificado no azevém pode ser considerado como uma característica particular da propriedade e um dos fatores de risco para ocorrência do surto de PEM.

A suplementação energética em pastagens de alta digestibilidade é uma alternativa para aumentar a velocidade de crescimento dos animais através de um melhor balanceamento dos nutrientes da dieta e de um aumento do consumo total de matéria seca. A substituição de parte do consumo de forragem pela ingestão de suplemento possibilita melhorar a produção animal por unidade de área (Restle et al. 2003). Entretanto, na propriedade onde ocorreu o surto, ao adotarem a estratégia nutricional de substituir parte do consumo de forragem pela ração com ingestão de $1 \%$ do peso vivo, proporcionou um incremento ainda maior na concentração de enxofre na dieta, favorecendo a ocorrência da PEM.

Outro fator que possa ter favorecido a ocorrência do surto de PEM é a presença do milho integral moído como um dos ingredientes da ração. A utilização de amido em quantidades excessivas na dieta, embora permita ao animal atingir sua capacidade produtiva, por apresentarem um teor de carboidratos de rápida fermentação relativamente alto, altera as condições fisiológicas do rúmen. A presença de amido propicia o desenvolvimento de bactérias amilolíticas e a fermentação mais rápida deste tipo de carboidrato propicia o acúmulo de ácidos orgânicos, o que pode resultar em redução do $\mathrm{pH}$, e criando uma condição considerada anormal e indesejável por afetar negativamente a saúde do rúmen e do animal (Millen et al. 2007). A redução do $\mathrm{pH}$ ruminal é considerada como um dos fatores associados ao desenvolvimento da PEM porque dietas com alto teor de enxofre e compostas por carboidrato de rápida fermentação, como no caso da ração peletizada fornecida aos animais do surto investigado, favorecem a diminuição do $\mathrm{pH}$ ruminal e proporcionam produções de gás sulfídrico ruminal em quantidades superiores a capacidade de oxidação do fígado, facilitando ação deste composto no sistema nervoso central (Sager et al. 1990, Gould et al. 1991).

A análise da quantidade de enxofre na água ingerida pelos bovinos apresentou valor de 2,4 mg/L e inferior a concentração considerada pelo Klasing et al. (2005) como nível máximo de enxofre na água (200mg de enxofre/L) tolerável 
para bovinos. A mensuração da concentração do enxofre nas fontes de água nas propriedades rurais deveria ser avaliada principalmente nas estações climáticas quentes, onde o consumo de enxofre oriundo da água pode estar elevado porque ocorre concomitantemente um aumento da concentração do sulfato na água e consumo da mesma, podendo ultrapassar os limites toleráveis estabelecidos por Klasing et al. (2005). Segundo Gould (2000) nas porções centro-norte e oeste dos EUA, a água contém elevada quantidade de sulfato. O sal do sulfato precipita quando ocorre a evaporação da água. A concentração do sulfato na água pode aumentar devida evaporação nas estações mais quentes do ano. O consumo de água pelos bovinos é dependente da temperatura ambiental e aumenta significativamente em elevadas temperaturas.

Os valores observados das concentrações de sulfeto de hidrogênio ruminal nos cinco bovinos do lote investigado variaram de 1.000 a $2.500 \mathrm{ppm}$, indicando que os animais ainda estavam consumindo enxofre em quantidades elevadas (Gould 2000). Gould et al. (1997), Loneragan et al (1998) e Niles et al (2002) utilizaram metodologia semeIhante de dosagem de $\mathrm{H}_{2} \mathrm{~S}$ ruminal em bovinos confinados e consideraram como valores normais concentrações inferiores a 500 ppm. Cunha et al. (2009) determinaram também a concentração de sulfeto de hidrogênio ruminal com a mesma técnica em bovinos Nelore saudáveis mantidos em pasto de Brachiaria decumbens com 0,15\% de enxofre na matéria seca e detectaram concentração máxima de $100 \mathrm{ppm}$ de gás sulfídrico ruminal, valores estes inferiores aos obtidos dos bovinos no Rio Grande do Sul que estavam ingerindo dieta com alto teor de enxofre.

Loneragan et al. (1998) realizaram dosagem de gás sulfídrico ruminal em um surto de PEM e obtiveram valores superiores aos detectados no presente estudo, com resultados que variaram de 2.300 a $13.500 p p m$ de $\mathrm{H}_{2} \mathrm{~S}$ ruminal. Entretanto, acredita-se que estes altos valores de sulfeto de hidrogênio ruminal descritos por Loneragan et al (1998) ocorreram porque o consumo total de enxofre na dieta e na água foi de $0,9 \%$ na matéria seca, enquanto a ingestão total de enxofre do presente relato foi de aproximadamente $0,38 \%$, justificando os resultados mais baixos da concentração de sulfeto de hidrogênio ruminal, visto que, a maioria do enxofre é reduzida $\mathrm{em}_{2} \mathrm{~S}$ no rúmen (Beauchamp et al. 1984, Kandylis 1983). Somando a isso as dosagens de $\mathrm{H}_{2} \mathrm{~S}$ no rúmen foram efetuadas aproximadamente quinze dias após o óbito do primeiro bezerro, não coincidindo com o pico de produção de sulfeto de hidrogênio. Resultados semelhantes foram observados por Gould et al. (1997) e Loneragan et al. (2005), que detectaram decréscimo nos valores de gás sulfídrico ruminal do décimo dia ao décimo quinto dia do inicio da indução experimental de PEM por ingestão excessiva de enxofre.

Pesquisas associando a PEM e o metabolismo do enxofre ruminal limitavam-se à determinação da concentração do ânion hidro-sulfeto no fluido ruminal (Gould et al. 1991). A dosagem de gás sulfídrico $\left(\mathrm{H}_{2} \mathrm{~S}\right)$ ruminal utilizando a técnica descrita por Gould et al. (1997) e adaptada nesta presente pesquisa caracterizou-se como um exame complementar prático porque pode ser realizada a campo e forneceu de forma imediata uma estimativa da concentração do sulfeto de hidrogênio ruminal.

Gould et al. (1997) ao compararam a técnica da dosagem de gás sulfídrico ruminal utilizando tubos colorimétricos com a cromatografia líquida de alta eficiência, não observaram diferenças significativas entre os resultados obtidos, confirmando que a metodologia empregada no presente estudo reflete valores confiáveis da concentração de $\mathrm{H}_{2} \mathrm{~S}$ ruminal, sendo desnecessário o uso de outras técnicas para este propósito.

No Brasil, a raiva é a enfermidade neurológica mais frequentemente diagnosticada nos bovinos revelando a importância sócio-econômica e de saúde pública das enfermidades que acometem o sistema nervoso central. Ao se realizar o diagnóstico diferencial das neuropatias dos bovinos, além da raiva deve-se também incluir todas as causas de PEM (Barros et al. 2006). O exame de imunofluorescência direta para raiva testou negativo para os dois animais, assim como não foi detectada a presença de chumbo nas amostras de fígado. Além disso, não foi identificada a presença do DNA viral do BoHV-5 realizado por meio da técnica da PCR.

\section{CONCLUSÃO}

O quadro clínico de síndrome cerebrocortical associado aos elevados valores do sulfeto de hidrogênio ruminal, alta ingestão de enxofre na dieta e os achados histopatológicos permitem estabelecer o excesso de enxofre como causador da polioencefalomalacia nos bovinos no Rio Grande do Sul.

Agradecimentos. - À Fundação de Amparo à Pesquisa do Estado de São Paulo (2006/05836-6) pelo apoio financeiro.

\section{REFERÊNCIAS}

Barreto Júnior R.A.R.A., Minervino A.H.H., Mori C.S., Sucupira M.C.A. \& Ortolani E.L. 2008. Levantamento da concentração de enxofre em capins e de sulfato inorgânico sérico em bovinos criados em fazendas no estado de São Paulo. Acta Sci. Anim. Sci. 30:327-332.

Barros C.S.L., Driemeier D., Dutra I.S. \& Lemos R.A.A. 2006. Doenças do Sistema Nervoso de Bovinos no Brasil. Vallée, Montes Claros, MG. 207p.

Beauchamp Jr R.O., Bus J.S., Popp J.A., Craig J., Boreiko C.J., Andjelkovich D.A. \& Leber P. 1984. A critical review of the literature on hydrogen sulfide toxicity. Crit. Rev. .Toxicol. 13:25-97.

Beke G.J. \& Hironaka R. 1991. Toxicity to beef cattle of sulfur in saline well water: A case study. Sci. Total Environ. 101:281-290.

Borges A.S., Mendes L.C. \& Kuchembuck M.R.G. 1999. Exame neurológico de grandes animais. I. Encéfalo. Revta Educ. Cont. CRMVSP 2:4-16.

Bulgin M.S., Lincoln S.D. \& Mather G. 1996. Elemental sulfur toxicosis in a flock of sheep. J. Am. Vet. Med. Assoc. 208:1063-1065.

Burgess B.A. 2008. Polioencephalomalacia. Large Anim.Vet. 8:1-6.

Claus M.P., Alfieri A.F., Folgueras-Flatschart A.V., Wosiacki S.R., Médici K.C. \& Alfieri A.A. 2005. Rapid detection and differentiation of bovine herpesvírus 1 and 5 glycoprotein $C$ gene in clinical specimens by multiplex-PCR. J. Virol. Meth. 128:183-188.

Coghlin C.L. 1944. Hydrogen sulphide poisoning in cattle. Can. J. Comp. Med. Vet. Sci. 8:111-113.

Cummings B.A., Gould D.H., Caldwell D.R. \& Hamar D.W. 1995. Ruminal microbial alterations associated with sulfide generation in steers with dietary sulfate-induced polioencephalomalacia. Am. J. Vet. Res. 56:1390-1395. 
Cunha P.H.J., Badial P.R., Oliveira Filho J.P., Amorim R.L., Cagnini D.Q. \& Borges A.S. 2008. Intoxicação experimental por enxofre em bovinos Nelore. $2^{\circ}$ Encontro Nacional de Diagnóstico Veterinário, Campo Grande, MS. Anais $2^{\circ}$ Endivet, p.20-21. (CD-ROM)

Cunha P.H.J., Badial P.R., Oliveira Filho J.P., Cagnini Q.D., Marinheiro M.F., Gorino A.C. \& Borges A.S. 2009. Avaliação da concentração do sulfeto de hidrogênio ruminal utilizando tubos colorimétricos em bovinos criados extensivamente. Anais 8 o Congresso Brasileiro de Buiatria, Belo Horizonte. Ciênc. Anim. Bras. (Supl.1):83-87.

Dickie C.W., Nelson R.J., Frazee D.G., Krugman L.D. \& Bronner E. 1979. Polioencephalomalacia in range cattle. J. Am. Vet. Med. Assoc. 175:460-462.

Dirksen G., Gründer H.D. \& Stöber M. 1993. Exame Clínico dos Bovinos. $3^{\text {a }}$ ed. Guanabara Koogan, Rio de Janeiro, p.373-381.

Gould D.H., McAllister M.M., Savage J.C. \& Hamar D.W. 1991. High sulfide concentrations in rumen fluid associated with nutritionally induced polioencephalomalacia in calves. Am. J. Vet. Res. 52:1164-1169.

Gould D.H., Cummings B.A. \& Hamar D.W. 1997. In vivo indicators of pathologic ruminal sulfide production in steers with diet-induced polioencephalomalacia. J. Vet. Diag. Invest. 9:72-76.

Gould D.H. 2000. Update on sulphur-related polioencephalomalacia. Vet. Clin. North Am., Food Anim. Pract. 16:481-496.

Hamlen H., Clark E. \& Janzen E. 1993. Polioencephalomalacia in cattle consuming water with elevated sodium sulfate levels: A herd investigation. Can. Vet. J. 34:153-158.

Harries N. 1987. Polioencephalomalacia in feedlot cattle drinking water high in sodium sulfate. Can. Vet. J. 28:717.

Haydock D. 2003. Sulfur-induced polioencephalomalacia in a herd of rotation cattle. Can. Vet. J. 44:828-829.

Hibbs C.M. \& Thilsted J.P. 1983. Toxicosis in cattle from contamined well water. Vet. Hum. Toxicol. 25:253-254.

Jeffrey M., Duff J.P., Higgins R.J., Simpson V.R., Jackman R., Jones T.O., Mechie S.C. \& Livesey, C.T. 1994. Polioencephalomalacia associated with the ingestion of ammonium sulphate by sheep and cattle. Vet. Rec. 134:343-348.

Jensen R., Griner L.A. \& Adams O.R. 1956. Polioencephalomalacia of cattle and sheep. J. Am. Vet. Med. Assoc. 129:311-321.

Kandylis K. 1983. Toxicology of sulfur in ruminants: A review. J. Dairy Sci. 67:2179-2187.

Klasing K.C., Goff J.P., Greger J.L. \& King J.C. 2005. Mineral Tolerance of Animals. $2^{\text {nd }}$ ed. National Academics Press, Washington DC., p.378-382.

Kul O., Karahan S., Basalan M. \& Kabakc N. 2006. Polioencephalomalacia in cattle: A consequence of prolonged feeding barley malt sprouts. J. Am. Vet. Med. Assoc. 53: 123-128.

Lima E.F., Riet-Correa F., Tabosa I.M., Dantas A.F.M. \& Medeiros J.M. 2005. Polioencefalomalacia em caprinos e ovinos na região semi-árida do Nordeste do Brasil. Pesq. Vet. Bras. 25:9-14.

Loneragan G.H., Gould D.H., Callan R.J., Sigurdson C.J. \& Hamar D.W. 1998. Association of excess sulfur intake and an increase in hydrogen sulfide concentrations in the ruminal gas cap of recently weaned beef calves with polioencephalomalacia. J. Am. Vet. Med. Assoc. 213:1599-1604.

Loneragan G.H., Gould D.H., Wagner J.J., Garry F.B. \& Thoren M.A. 2005. The magnitude and patterns of ruminal hydrogen sulfide production, blood thiamine concentration and mean pulmonary arterial pressure in feedlot steers consuming water of different sulfate concentrations. Bov. Pract. 39:16-22.

Low J.C., Scott P.R., Howie F., Lewis M., Fitzsimons J. \& Spence J.A. 1996. Sulphur-induced polioencephalomalacia in lambs. Vet. Rec. 138:327-329.

McAllister M.M., Gould D.H. \& Hamar D.W. 1992. Sulphide-induced polioencephalomalacia in lambs. J. Comp. Pathol. 106:267-278.
McAllister M.M., Gould D.H. \& Raisbeck M.F. 1997. Evaluation of ruminal sulfide concentrations and seasonal out breaks of polioencephalomalacia in beef cattle in a feedlot. J. Am. Vet. Med. Assoc. 2:1275-1279.

McKenzie R.A., Carmichael A.M., Schibrowski M.L., Duigan S.A., Gibson J.A. \& Taylor J.D. 2009. Sulfur-associated polioencephalomalacia in cattle grazing plants in the Family Brassicaceae. Aust. Vet. J. 87:27-32.

Mella C.M., Perez-Oliva O. \& Loew F.M. 1976. Induction of bovine polioencephalomalacia with a feeding system based on molasses and urea. Rev. Canad. Rech. Vet. 40:104-110.

Millen D.D., Arrigoni M.B.D. \& Pacheco L.D.L. 2007. Manipulação da fermentação ruminal: saúde animal. Pubvet 1:54-89.

Nakazato L., Lemos R.A.A. \& Riet-Correa F. 2000. Polioencefalomalacia em bovinos nos estados de Mato Grosso do Sul e São Paulo. Pesq. Vet. Bras. 20:119-125.

National Research Council - NRC. 2000. Nutrient requirements of beef cattle. $7^{\text {th }}$ ed. National Academy of Sciences, Washington, DC, p.102112.

Niles G.A., Morgan S.E. \& Edwards W.C. 2000. Sulfur-induced polioencephalomalacia in stocker calves. Vet. Human Toxicol. 42:290291.

Niles G.A., Morgan S., Edwards W.C. \& Lalman D. 2002. Effects of dietary sulfur concentrations on the incidence and pathology of polioencephalomalacia in weaned beef calves. Vet. Human Toxicol. 44:70-72.

Raisbeck M.F. 1982. Is polioencephalomalacia associated with highsulfate diets? J. Am. Vet. Med. Assoc. 180:1303-1305.

Restle J., Vaz F., Fernandes R.A.C., Pascoal L.L., Menezes L.F.G. \& Pacheco P.S. 2003. Características de carcaça e da carne de vacas de descarte de diferentes genótipos Charolês $\times$ Nelore terminadas em confinamento. Ciência Rural 33:345-350.

Rousseaux C.G., Olkowski A.A., Chauvet A., Gooneratne S.R. \& Christenson D.A. 1991. Ovine polioencephalomalacia associated with dietary sulphur intake. J. Am. Vet. Med. Assoc. 38:229-239.

Roso D. 2007. Recria de bezerras de corte em alternativas de uso da pastagem de azevém (Lolium multiflorum Lam.). Dissertação de Mestrado em Produção Animal, Centro de Ciências Rurais, Universidade Federal de Santa Maria, RS. 87p.

Sager L.R., Hamar D.W. \& Gould D.H. 1990. Clinical and biochemical alterations in calves with nutritionally induced polioencephalomalacia. Am. J. Vet. Res. 51:1969-1974.

Sant'Ana F.J.F., Rissi D.R., Lucena R.B., Lemos R.A.A., Nogueira A.P.A. \& Barros C.S.L. 2009a. Polioencefalomalacia em bovinos: epidemiologia, sinais clínicos e distribuição das lesões no encéfalo. Pesq. Vet. Bras. 29:487-497.

Sant'Ana F.J.F., Lemos R.A.A., Nogueira A.P.A., Togni M., Tessele B. \& Barros C.S.L. 2009b. Polioencefalomalacia em ruminantes. Pesq. Vet. Bras. 29:681-694.

Tebaldi F.L.H., Silva J.F.C., Vasquez H.M. \& Thiebauts J.T.L. 2000. Mineral composition of pastures in the North and Northwest regions of Rio de Janeiro State. I. Calcium, phosphorus, magnesium, potassium, sodium and sulfur. Revta Bras. Zootec. 29:603-615.

Traverso S.D., Colodel E.M., Loretti A.P., Seitz A.L., Correa A.M., Krauspenhar C. \& Driemeier D. 2001. Polioencefalomalacia em bovinos leiteiros no Rio Grande do Sul, suplementados com enxofre. Anais X Encontro Nacional de Patologia Veterinária, Pirassununga, SP, p.72.

Winchester C. F. \& Morris. M.J. 1956. Water intake rates of cattle. J. Anim. Sci. 15:722-740.

Wunsch C., Barcellos J.O.J., Prates E.R., Costa E.C., Montanholi Y.R. \& Brandão F. 2006. Macrominerais para bovinos de corte nas pastagens nativas dos Campos de Cima da Serra, RS. Ciência Rural 36:1258-1264. 